\title{
VALIDAÇ̃̃O DO APLICATIVO COMPUTACIONAL SEEDSOLVE PARA PREVISẪO DAS PERDAS DE GERMINAÇÃO E VIGOR DE SEMENTES ARMAZENADAS ${ }^{1}$
}

\author{
ROBERTO SINÍCIO², MARIA CARMEM BHERING², DEBORAH DE SOUZA VIDIGAL ${ }^{3}$, \\ DENISE CUNHA F. SANTOS DIAS ${ }^{4}$.
}

\begin{abstract}
RESUMO - Objetivou-se validar o aplicativo computacional SEEDSOLVE para previsão das perdas de germinação e vigor de sementes ortodoxas armazenadas. A validação foi realizada comparandose valores calculados com valores experimentais das perdas de germinação e vigor de sementes de três cultivares de milho e de soja armazenadas em laboratório, durante um período de 210 dias. Sementes de milho e soja, com três níveis de grau de umidade (11, 13 e 15\% para o milho e 9, 11 e $13 \%$ para a soja), foram acondicionadas em embalagens de plástico polietileno e armazenadas em câmaras BOD sob três temperaturas $\left(15,25\right.$ e $\left.35^{\circ} \mathrm{C}\right)$. Os resultados das comparações dos dados calculados e experimentais de germinação e vigor durante o armazenamento de sementes dos três lotes de cada espécie, sob diferentes condições de armazenagem, permitiram concluir que o SEEDSOLVE prediz com razoável precisão as perdas de germinação e vigor de sementes de milho e de soja armazenadas.
\end{abstract}

Termos para indexação: Programa de computador, sementes, modelos matemáticos, longevidade, armazenamento.

\section{VALIDATION OF THE SOFTWARE SEEDSOLVE FOR PREDICTING LOSSES OF GERMINATION AND VIGOR OF STORED SEEDS}

\begin{abstract}
The objective of this study was validate the software SEEDSOLVE for predicting the germination and vigor losses in stored orthodox seeds. The validation was accomplished by comparing the calculated and experimental values of the germination and vigor losses in three seed lot sof corn and soybean stored in the laboratory, during a period of 210 days. The corn and soybean seeds, with three levels of moisture content $(11,13$, and 15\% for corn and 9,11 , and $13 \%$ for soybean), were packed in polyethylene bags and stored in incubators at three temperatures $\left(15,25\right.$, and $\left.35^{\circ} \mathrm{C}\right)$. The results of the comparisons of the calculated and experimental data of germination and vigor that occurred during the storage of the three seed lots, under different storage conditions, allowed the conclusion that the SEEDSOLVE predicted the germination and vigor losses in stored corn and soybean seeds with reasonable precision.
\end{abstract}

Index terms: Software, seeds, mathematical models, longevity, storage.

${ }^{1}$ Submetido em 05/09/2007. Aceito para publicação em, 30/04/2008. Financiado pela FAPEMIG e SEBRAE.

${ }^{2}$ Pesquisadores do Departamento de Fitotecnia, Universidade Federal de Viçosa, 36570-000 Viçosa, MG. rsinicio@ufv.br; mbhering@ufv.br
${ }^{3}$ Doutoranda do Departamento de Fitotecnia, Universidade Federal de Viçosa, 36570-000 Viçosa, MG. E-mail: dsvidigal@gmail.com

${ }^{4}$ Prof. Associado, Departamento de Fitotecnia, Universidade Federal de Viçosa, 36570-000 Viçosa, MG. E-mail: dcdias@ufv.br 


\section{INTRODUÇÃO}

A crescente demanda pela qualidade total nas empresas produtoras de sementes têm exigido a implementação de testes cada vez mais seguros com o objetivo de garantir a qualidade do produto final. O controle da qualidade total, entretanto, somente poderá ser exercido, se a qualidade da semente for acompanhada em todas as fases do processo de produção, desde a escolha do cultivar até a comercialização. Na fase pós-colheita, o armazenamento é uma das etapas que mais influencia a qualidade das sementes. Nesta etapa, o uso de modelos matemáticos para a previsão das perdas de qualidade das sementes, permite otimizar o dimensionamento e o gerenciamento de sistemas de armazenagem.

A previsão da perda da viabilidade de sementes armazenadas é importante tanto para a manutenção de bancos de germoplasma como para o gerenciamento do armazenamento de sementes. Assim, há a necessidade de adoção de modelos confiáveis de longevidade das sementes (Mead e Gray, 1999). A necessidade de monitoramento da qualidade das sementes armazenadas é diminuída na medida em que são desenvolvidos modelos matemáticos mais precisos para predizer a perda de viabilidade. O monitoramento da viabilidade de sementes é a etapa que exige maior demanda de mão-de-obra para a manutenção de bancos de germoplasma (Bewley e Black, 1994).

Grande parte do germoplasma é armazenada como semente em muitos centros de recursos genéticos no mundo. Nesses centros o armazenamento de sementes é realizado em longo prazo, geralmente por mais de cinco anos, com a manutenção da viabilidade mais alta possível, sendo a manutenção da diversidade genética de plantas uma preocupação mundial (Vertucci e Ross, 1990). A conservação dos recursos genéticos é extremamente importante em programas de melhoramento vegetal, particularmente em relação à resistência a doenças, estresse e produtividade (Bewley e Black, 1994).

Modelos matemáticos tais como o modelo de probit, descrito por Ellis e Roberts (1980) para previsão da perda de germinação, são utilizados para estabelecer as recomendações de armazenagem comercial e em bancos de germoplasma. Neste modelo, entretanto, sementes de cada espécie tem comportamento diferente durante o armazenamento nas mesmas condições. Logo, há a necessidade de se determinar coeficientes para cada espécie de semente armazenada. No modelo de Ellis e Roberts (1980), a curva de sobrevivência das sementes, pode ser descrita por:

$$
v=K i-p / 10^{\left(K E-C W \log m-C H t-C Q t^{2}\right)}
$$

em

que: $v=$ viabilidade das sementes (probit); $K i=$ viabilidade inicial das sementes (probit); $p=$ período de armazenamento (dias); $m=$ grau de umidade ( $\%$, base úmida); $t=$ temperatura $\left({ }^{\circ} \mathrm{C}\right) ; \mathrm{KE}, \mathrm{CW}, \mathrm{CH}$ e $\mathrm{CQ}=$ coeficientes específicos para cada espécie, independentes do genótipo e das condições de préestocagem.

A perda da germinação de sementes armazenadas, em função do período de armazenamento, da temperatura e do grau de umidade, tem sido prevista com sucesso para muitas espécies e variedades, utilizando-se o modelo de Ellis e Roberts (1980). Os coeficientes $K E, C W, C H$ e $C Q$ deste modelo já foram determinados, por diferentes pesquisadores, para mais de 77 variedades de 48 espécies (Ellis e Roberts, 1980; Ellis et al., 1982; Hong et al., 1996; Sinício, 2007a; Sinício et al., 2008; Usberti e Gomes, 1998).

$K i$ é uma constante que representa uma estimativa da qualidade inicial das sementes, sendo específica para cada lote de sementes, dependente do genótipo e das condições de pré-armazenamento, bem como da interação entre eles (Ellis e Roberts, 1980). Para determinar Ki com maior precisão, Ellis e Roberts (1980) sugerem que essa determinação seja feita por meio do teste de envelhecimento acelerado, em que as sementes são rapidamente deterioradas, sob condições constantes e adversas de umidade e temperatura, por determinado período de tempo. Testes de germinação sucessivos seriam realizados com amostras retiradas em intervalos regulares nas condições acima citadas, calculando-se assim a curva de sobrevivência das sementes por meio da análise de probit (Finney, 1971). O valor de Ki poderia ser determinado, na interceptação da curva de sobrevivência das sementes plotada em probit, com o tempo zero de armazenamento.

Mauri et al. (2007) equacionou o valor de $K i$ para sementes de soja em função do resultado dos testes de germinação e envelhecimento acelerado iniciais, conforme segue: $\quad K i=0,1748+0,8609 G+0,1852 E A$

em que: $G=$ Germinação inicial (probit); $E A=$ Envelhecimento acelerado inicial (probit).

Sinício (2004) desenvolveu uma equação generalizada de longevidade (EGL) para calcular a perda de germinação e vigor de qualquer semente ortodoxa armazenada. Nesta pesquisa, foram determinados os coeficientes $K E, C W$, $C H$ e $C Q$ do modelo de probit (Equação 1) em função das 
frações de carboidratos, lipídios e proteínas, contidas em sementes ortodoxas, conforme segue:

$$
\begin{aligned}
& K E=a_{0}+a_{1} X_{C}+a_{2} X_{C}^{2}+a_{3} X_{L}+a_{4} X_{L}^{2} \\
& C W=-\left(b_{0}+b_{1} X_{C}\right) \\
& C H=-\left(c_{0}+c_{1} X_{L}+c_{2} X_{L}^{2}\right. \\
& C Q=-\left(d_{0}+d_{1} X_{P}^{2}\right)
\end{aligned}
$$

em que $X_{C} X_{L}$ e $X_{P}$ são as frações de carboidratos, lipídios e proteínas, respectivamente (g/g de matéria seca). Os valores dos coeficientes (desvios padrões entre parênteses) foram: $a_{0}=2,9467(0,10095) ; a_{1}=13,391(0,24921) ; a_{2}=-6,2564$ $(0,17253) ; a_{3}=6,3005(0,20572) ; a_{4}=-10,575(0,24846)$; $b_{0}=-2,4824(0,034214) ; b_{1}=-4,0170(0,053815) ; c_{0}=$ $-0,031833(0,00028810) ; \quad c_{1}=-0,16261(0,0036194) ; c_{2}$ $=0,31637(0,0066431) ; d_{0}=-0,47012 \times 10^{-3}\left(5,0719 \times 10^{-6}\right) ; \mathrm{e}^{2}$ $d_{1}=0,14418 \times 10^{-2}\left(5,3006 \times 10^{-5}\right)$. Foram utilizadas sementes de seis espécies (amendoim, cevada, grão-de-bico, feijão caupi, soja e sorgo).

Mais recentemente, Sinício (2007b) desenvolveu o aplicativo computacional SEEDSOLVE para previsão das perdas de germinação e vigor de sementes ortodoxas armazenadas, com base no modelo matemático de Ellis e Roberts (1980). Neste aplicativo existe um banco de dados com uma lista de 77 cultivares de 48 espécies e a EGL desenvolvida por Sinício (2004) foi implementada no SEEDSOLVE.

Por meio do SEEDSOLVE é possível: 1) calcular a germinação e o vigor finais das sementes armazenadas, dados de germinação e vigor iniciais, o período e as condições de armazenamento (temperatura e grau de umidade); 2) calcular o período máximo para armazenamento das sementes, dados de germinação e vigor iniciais, a germinação final e as condições de armazenamento; 3) calcular a temperatura máxima para armazenamento das sementes, dados de germinação e o vigor iniciais, a germinação final, o período e o grau de umidade das sementes; 4) calcular o grau de umidade máximo para armazenamento das sementes, dados de germinação e de vigor iniciais, a germinação final, o período e a temperatura das sementes.

O SEEDSOLVE foi escrito na linguagem DELPHI ${ }^{\mathrm{TM}}$. A plataforma utilizada foi o MS-Windows ${ }^{\mathrm{TM}}$, oferecendo ao usuário uma interface simples, sem a necessidade de treinamento especial na operação do aplicativo.

Ovalor de Kino aplicativo SEEDSOLVE foi equacionado por Mauri et al. (2007) para sementes de soja em função dos resultados nos testes de germinação e envelhecimento acelerado iniciais.

As constantes do modelo de probit para as sementes listadas no aplicativo foram obtidas de Hong et al. (1996), exceto para as seguintes sementes: amendoim (Arachis hypogaea L.) de Usberti e Gomes (1998); cevada (Hordeum distichum L.) de Ellis e Roberts (1980); caupi (Vigna unguiculata), grão-de-bico (Cicer arietinum) e soja (Glycine max (L.) Merr.) de Ellis et al. (1982); tomate (Lycopersicum esculentum Mill) de Sinício et al. (2008) e café (Coffea arabica L.) de Sinício (2007a).

Considerando a importância do aplicativo computacional SEEDSOLVE desenvolvido por Sinício (2007b) para calcular as perdas de germinação e vigor de sementes ortodoxas armazenadas, objetivou-se validá-lo pela comparação de valores experimentais com aqueles calculados pelo aplicativo.

\section{MATERIAL E MÉTODOS}

O presente trabalho foi conduzido no Departamento de Fitotecnia da Universidade Federal de Viçosa. Sementes de milho (cultivares SHS4070, SHS4080 e SHS30301) e de soja (cultivares Vencedora, Valiosa e Garantia), já beneficiadas, foram fornecidas pelas empresas Santa Helena Sementes de Sete Lagoas, MG e Agromen de Pirapora, MG, respectivamente. Os híbridos SHS4070 e SHS4080 são duplos e o SHS3031 é variedade.

A qualidade das sementes foi avaliada inicialmente e durante o armazenamento por meio dos seguintes testes e determinações: a) grau de umidade: determinado pelo método da estufa a $105 \pm 3^{\circ} \mathrm{C}$ por 24 horas (Brasil, 1992); b) germinação (TG): foi conduzido em rolo de papel Germitest, umedecido com água destilada na proporção de 2,5 vezes o peso do papel seco, em germinador a $25^{\circ} \mathrm{C}$, com quatro subamostras de 50 sementes por repetição, sendo os resultados expressos em porcentagem de plântulas normais (Brasil, 1992); c) teste de frio (TF): foi conduzido para sementes de milho de maneira semelhante ao TG, exceto que após a confecção dos rolos de papel, estes foram colocados em sacos de polietileno em incubadora BOD a $10^{\circ} \mathrm{C}$ durante sete dias. Em seguida, os rolos foram transferidos para o germinador a $25^{\circ} \mathrm{C}$ e a porcentagem de plântulas normais foi determinada no quarto dia (Cícero e Vieira, 1994); d) tetrazólio (TZ): foi utilizado para avaliar o vigor (classes 1 a 3 ) das sementes de soja. Foram utilizadas quatro repetições de 25 sementes que, inicialmente, foram pré-condicionadas entre folhas de 
papel-toalha umedecidas e acondicionadas em germinador a $25^{\circ} \mathrm{C}$ durante $16 \mathrm{~h}$. Após esse período, as sementes foram colocadas imersas em solução de sal 2,3,5 cloreto de trifeniltetrazólio na concentração de $0,075 \%$, e mantidas a $35^{\circ} \mathrm{C}$ por período aproximado de 150 a $180 \mathrm{~min}$, quando apresentaram coloração adequada para serem avaliadas (França Neto et al., 1998). As sementes foram avaliadas individualmente, seccionando-as longitudinalmente seguida da observação de ocorrência de danos (mecânico, secagem, processamento) nas partes externas e internas dos cotilédones, dando atenção especial ao eixo embrionário (França Neto, 1994). Observou-se ainda, a diferenciação de cores dos tecidos, de acordo com os critérios estabelecidos por Moore (1985).Os resultados foram expressos em porcentagem de sementes viáveis vigorosas.

Experimentos foram conduzidos para avaliar o efeito da temperatura, grau de umidade, tempo de armazenagem e composição química das sementes (fração de carboidratos, cinzas, lipídios e proteínas) na perda de germinação e vigor durante o período de armazenamento. As sementes das três cultivares, com graus de umidade de 10,13 e $15 \%$ para o milho e 9, 11 e 13\% para a soja, foram armazenadas até o máximo de 210 dias, sob três temperaturas $\left(10,25\right.$ e $\left.35^{\circ} \mathrm{C}\right)$. Foram necessários, para cada cultivar, cerca de $20 \mathrm{~kg}$ de sementes de soja e $25 \mathrm{~kg}$ de milho.

Inicialmente e conforme a necessidade, as sementes tiveram o grau de umidade ajustado mediante processo de secagem. A secagem em baixa temperatura, máximo de $35^{\circ} \mathrm{C}$, feita em um secador de leito fixo foi utilizada quando o grau de umidade das sementes estava acima daquele desejado. Após o ajuste do grau de umidade, as sementes foram acondicionadas em embalagens de polietileno impermeáveis à água (cerca de 600 sementes por embalagem), e permaneceram em repouso na temperatura de $5^{\circ} \mathrm{C}$ durante três dias, para redistribuição da umidade no interior das mesmas.

Posteriormente, as sementes com diferentes graus de umidade foram armazenadas em incubadoras BOD nas temperaturas constantes de 15,25 e $35^{\circ} \mathrm{C}$ durante os períodos de armazenagem apresentados na Tabela 1. A qualidade fisiológica e o grau de umidade das sementes foram avaliados inicialmente e nos sete intervalos de tempo apresentados na Tabela 1. Esses períodos de armazenamento das sementes foram estimados utilizando-se equações de longevidade disponíveis na literatura (Ellis et al., 1982; Hong et al., 1996).

Foram determinadas ainda as quantidades de carboidratos totais, cinzas, lipídios e proteínas contidas nas sementes das três cultivares de milho e de soja, no laboratório do
Departamento de Zootecnia da UFV, de acordo com as normas analíticas do Instituto Adolfo Lutz (1985).

\section{TABELA 1. Períodos de armazenamento (dias) das sementes de milho e soja em função das condições de temperatura e grau de umidade.}

\begin{tabular}{|c|c|c|c|c|c|c|}
\hline \multirow{3}{*}{$\begin{array}{c}\text { Temperatura } \\
\left({ }^{\circ} \mathrm{C}\right)\end{array}$} & \multicolumn{6}{|c|}{ Grau de Umidade (\%) } \\
\hline & \multicolumn{3}{|c|}{ Milho } & \multicolumn{3}{|c|}{ Soja } \\
\hline & 11 & 13 & 15 & 9 & 11 & 13 \\
\hline 15 & 210 & 210 & 210 & 210 & 210 & 210 \\
\hline 25 & 210 & 210 & 150 & 210 & 210 & 210 \\
\hline 35 & 150 & 70 & 30 & 210 & 90 & 40 \\
\hline
\end{tabular}

Para validação do aplicativo computacional SEEDSOLVE, foram comparados os resultados simulados com aqueles obtidos experimentalmente em laboratório. Assim, os valores experimentais de perda de germinação e vigor para as sementes das três cultivares de milho e soja, durante o armazenamento foram comparados com os valores de perda de germinação calculados pelo aplicativo, mediante cálculo do erro padrão em porcentagem de germinação.

As perdas de germinação e vigor foram calculadas em função da qualidade inicial, do período de armazenagem, do grau de umidade e da temperatura do ambiente das sementes. A equação generalizada de longevidade foi validada pela comparação dos resultados calculados com aqueles obtidos experimentalmente utilizando-se a composição química relacionada às frações de carboidratos, cinzas, lipídios e proteínas determinadas nas sementes de milho e soja.

\section{RESULTADOS E DISCUSSÃO}

Os valores médios iniciais de grau de umidade e qualidade, determinados para as sementes de milho e soja (Tabela 2), foram utilizados na comparação dos resultados experimentais e simulados de perdas de germinação e vigor ocorridos durante o armazenamento, nas temperaturas de 15,25 e $35^{\circ} \mathrm{C}$. Os cálculos foram realizados colocando-se os valores médios de germinação e vigor iniciais (Tabela 2), para cada cultivar e grau umidade, no lugar de $K i$ (Equação 1), embora Ellis e Roberts (1980) tenham sugerido que $K i$ seja determinado por meio de testes de envelhecimento acelerado. Isto se justifica porque nas análises de regressão linear para determinar $K i$ com base nas curvas de sobrevivência das 
sementes, foram obtidos baixos valores dos coeficientes de determinação ajustado e dos elevados erros padrões (médias de
$28,9 \pm 39,5 \%$ e $0,21 \pm 0,12$ probit para o milho e de $24,7 \pm 35,5 \%$ e $0,22 \pm 0,08$ probit para a soja, respectivamente).

TABELA 2. Valores médios iniciais de grau de umidade (U), germinação (G) e vigor* (V) das sementes de milho e soja

\begin{tabular}{|c|c|c|c|c|}
\hline Espécie & Cultivar & $\mathrm{U}$ & $\mathrm{G}$ & $\mathrm{V}$ \\
\hline \multirow{9}{*}{ Milho } & \multirow{3}{*}{ SHS4070 } & 11,6 & 95 & 95 \\
\hline & & 13,4 & 92 & 93 \\
\hline & & 15,0 & 91 & 91 \\
\hline & \multirow{3}{*}{ SHS4080 } & 11,3 & 96 & 95 \\
\hline & & 13,1 & 95 & 96 \\
\hline & & 16,8 & 99 & 95 \\
\hline & \multirow{3}{*}{ SHS3031 } & 11,7 & 92 & 82 \\
\hline & & 13,1 & 89 & 90 \\
\hline & & 12,9 & 88 & 85 \\
\hline \multirow{9}{*}{ Soja } & \multirow{3}{*}{ Vencedora } & 9,0 & 89 & 84 \\
\hline & & 11,1 & 90 & 85 \\
\hline & & 12,9 & 96 & 87 \\
\hline & \multirow{3}{*}{ Valiosa } & 9,0 & 71 & 68 \\
\hline & & 10,8 & 77 & 81 \\
\hline & & 13,0 & 82 & 80 \\
\hline & \multirow{3}{*}{ Garantia } & 9,4 & 89 & 84 \\
\hline & & 10,7 & 89 & 86 \\
\hline & & 13,7 & 94 & 91 \\
\hline
\end{tabular}

*Teste de frio para milho e teste de tetrazólio para soja.

Os baixos valores dos coeficientes de determinação ajustado e dos elevados erros padrões obtidos tanto para o milho quanto para a soja, significam que houve um ajuste relativamente pobre dos dados de sobrevivência das sementes à Equação 1, sob condições constantes de temperatura e grau de umidade. Os erros padrões médios obtidos, entretanto, estão dentro dos limites relatados por outros pesquisadores. Pieta Filho et al. (1992) obtiveram desvio padrão médio na determinação de $K i$ de $0,16 \pm 0,06$ probit (seis lotes de cevada e oito lotes de trigo) e Fabrizius et al. (1999) obtiveram $0,46 \pm 0,31$ probit (12 lotes de soja).

Nas Tabelas 3 e 4 são apresentados os erros padrões das equações utilizadas no aplicativo para calcular as perdas de germinação e vigor de sementes de milho e soja, respectivamente, armazenadas nas temperaturas de 15, 25 e $35^{\circ} \mathrm{C}$, com diferentes graus de umidade inicial. Observa-se que os erros padrões foram bem menores para as equações do milho (opção Milho no aplicativo) e EGL, quando se utilizaram, por exemplo, fatores de correção iguais a 1,10 e 1,09 para a germinação e o vigor, respectivamente (Tabela 3). A equação do milho foi obtida de Hong et al. (1996) e a equação EGL (Equações 1 e de 3 a 6) foi obtida utilizando-se as frações de carboidratos, lipídios e proteínas determinadas para as sementes dos três cultivares de milho, conforme composição química média dos cultivares de milho apresentada na Tabela 5.

As diferenças observadas entre os erros padrões e coeficientes de variação para diferentes cultivares foram menores para o milho (Tabela 3) quando comparadas com as da soja (Tabela 4). A utilização de fatores de correção resultou em alteração dessas diferenças tanto para o milho como para a soja, principalmente quando se utilizou a equação generalizada de longevidade. Estes resultados indicam a necessidade de se determinar fatores de correção para cada cultivar. Na prática recomenda-se revisar os fatores de correção para cada cultivar após uma ou duas safras. 
TABELA 3. Erro padrão das equações Milho e equação generalizada de longevidade (EGL) do aplicativo SEEDSOLVE para calcular as perdas de germinação $(G)$ e vigor (V) de sementes de milho armazenadas nas temperaturas de 15,25 e $35^{\circ} \mathrm{C}$, com diferentes graus de umidade inicial.

\begin{tabular}{|c|c|c|c|c|c|c|}
\hline \multirow{2}{*}{ Teste } & \multirow{2}{*}{ Cultivar } & \multirow{2}{*}{$\begin{array}{c}\mathrm{N}^{0} \text { de Observações } \\
\text { Experimentais }\end{array}$} & \multicolumn{4}{|c|}{ Erro Padrão das Equações (\%) } \\
\hline & & & Milho & EGL & Milho* & $\mathrm{EGL}^{*}$ \\
\hline \multirow{3}{*}{ G } & SHS4070 & 72 & 34 & 19 & 23 & 12 \\
\hline & SHS4080 & 71 & 32 & 20 & 24 & 17 \\
\hline & SHS3031 & 66 & 31 & 19 & 23 & 13 \\
\hline \multirow{3}{*}{$\mathrm{V}$} & SHS4070 & 72 & 33 & 19 & 24 & 13 \\
\hline & SHS4080 & 71 & 30 & 19 & 23 & 17 \\
\hline & SHS3031 & 66 & 26 & 17 & 21 & 14 \\
\hline G & \multirow{2}{*}{\multicolumn{2}{|c|}{ Média (\%) }} & 32,3 & 19,3 & 23,3 & 14,0 \\
\hline $\mathrm{V}$ & & & 29,7 & 18,3 & 22,7 & 14,7 \\
\hline G & \multirow{2}{*}{\multicolumn{2}{|c|}{ Coeficiente de Variação (\%) }} & 4,7 & 3 & 2,5 & 18,9 \\
\hline $\mathrm{V}$ & & & 11,8 & 6,3 & 6,7 & 14,2 \\
\hline
\end{tabular}

*Usando fator de correção igual a 1,10 para a germinação e 1,09 para o vigor

TABELA 4. Erro padrão das equações Soja1 e equação generalizada de longevidade (EGL) do aplicativo SEEDSOLVE para calcular as perdas de germinação $(G)$ e vigor $(V)$ de sementes de soja armazenadas nas temperaturas de 15,25 e $35^{\circ} \mathrm{C}$, com diferentes graus de umidade inicial.

\begin{tabular}{|c|c|c|c|c|c|c|}
\hline \multirow{2}{*}{ Teste } & \multirow{2}{*}{ Cultivar } & \multirow{2}{*}{$\begin{array}{c}\text { № de Observações } \\
\text { Experimentais }\end{array}$} & \multicolumn{4}{|c|}{ Erro Padrão das Equações (\%) } \\
\hline & & & Soja1 & EGL & Soja1 $^{*}$ & $\mathrm{EGL}^{*}$ \\
\hline \multirow{3}{*}{ G } & Vencedora & 71 & 28 & 26 & 8 & 8 \\
\hline & Valiosa & 71 & 25 & 32 & 10 & 16 \\
\hline & Garantia & 69 & 26 & 34 & 11 & 17 \\
\hline \multirow{3}{*}{$\mathrm{V}$} & Vencedora & 71 & 27 & 25 & 13 & 11 \\
\hline & Valiosa & 71 & 20 & 25 & 17 & 20 \\
\hline & Garantia & 69 & 23 & 29 & 16 & 21 \\
\hline G & \multirow{2}{*}{\multicolumn{2}{|c|}{ Média (\%) }} & 26,3 & 30,7 & 9,7 & 13,7 \\
\hline $\mathrm{V}$ & & & 23,3 & 26,3 & 15,3 & 17,3 \\
\hline G & \multirow{2}{*}{\multicolumn{2}{|c|}{ Coeficiente de Variação (\%) }} & 5,8 & 13,6 & 15,8 & 36,1 \\
\hline $\mathrm{V}$ & & & 15,1 & 8,8 & 13,6 & 31,8 \\
\hline
\end{tabular}

* Usando fator de correção igual a 1,20 para a germinação e 1,15 para o vigor. 
TABELA 5. Composição química média das três variedades de milho e soja dada pela fração média de cinzas, proteínas, lipídios e carboidratos ${ }^{1}$.

\begin{tabular}{cccccc}
\hline \multirow{2}{*}{ Espécie } & Variedade & \multicolumn{3}{c}{ Fração média das amostras (decimal, b.s.) } \\
\cline { 3 - 5 } & SHS 4070 & $0,0136 \mathrm{a}$ & $0,0933 \mathrm{c}$ & $0,0400 \mathrm{~d}$ & $0,8530 \mathrm{f}$ \\
\hline \multirow{2}{*}{ Milho } & SHS 4080 & $0,0105 \mathrm{~b}$ & $0,0879 \mathrm{c}$ & $0,0555 \mathrm{e}$ & $0,8461 \mathrm{f}$ \\
& SHS 3031 & $0,0134 \mathrm{a}$ & $0,0932 \mathrm{c}$ & $0,0419 \mathrm{~d}$ & $0,8514 \mathrm{f}$ \\
\hline \multirow{3}{*}{ Soja } & Vencedora & $0,0435 \mathrm{~g}$ & $0,4074 \mathrm{i}$ & $0,2016 \mathrm{k}$ & $0,3475 \mathrm{l}$ \\
& Valiosa & $0,0416 \mathrm{~h}$ & $0,4353 \mathrm{j}$ & $0,2228 \mathrm{k}$ & $0,3003 \mathrm{~m}$ \\
& Garantia & $0,0429 \mathrm{~h}$ & $0,4461 \mathrm{j}$ & $0,2109 \mathrm{k}$ & $0,3001 \mathrm{~m}$ \\
\hline
\end{tabular}

${ }^{1}$ Médias seguidas de mesma letra não diferem entre si pelo Teste de Tukey a 5\% de probabilidade.

Verifica-se que as equações da soja (opção Sojal no aplicativo) e EGL também apresentaram erros padrões bem menores, quando se utilizaram, por exemplo, fatores de correção iguais a 1,20 e 1,15 para a germinação e o vigor, respectivamente (Tabela 4). A equação da soja foi obtida de Hong et al. (1996) e a equação EGL foi obtida utilizando-se as frações de carboidratos, lipídios e proteínas determinadas para as sementes dos três cultivares de soja (Tabela 5). A recomendação prática é a mesma dada anteriormente para o milho, isto é, devem-se revisar os fatores de correção para cada cultivar após uma ou duas safras.

A equação EGL, comparada com a equação do milho (Tabela 3), resultou em menores erros padrões tanto para a germinação quanto para o vigor, para sementes de todas as cultivares de milho. No caso da soja (Tabela 4), a equação EGL resultou em erros padrões menores do que a equação da soja apenas para a cultivar Vencedora. Esses resultados permitem recomendar o uso da equação EGL para sementes de milho e para sementes de soja cultivar Vencedora.

A fração de lipídios do cultivar SHS4080 diferiu daquela das outras cultivares de milho e as frações de carboidratos e proteínas da cultivar Vencedora diferiram daquelas das outras cultivares de soja (Tabela 5). Valores simulados para as duas situações hipotéticas permitem estudar, por exemplo, o efeito da composição química (Tabela 5) na longevidade de sementes: a) Sementes das cultivares SHS4070 e SHS4080 com valores iniciais de $95 \%$ de germinação e $93 \%$ de vigor (TF), armazenadas durante 210 dias a $25^{\circ} \mathrm{C}$ e com $13 \%$ de grau de umidade, resultaram em germinação e vigor finais de 69 e $60 \%$ e 73 e $65 \%$, respectivamente; b) Sementes dos cultivares Vencedora e Valiosa com valores iniciais de 95\% de germinação e $93 \%$ de vigor (TZ), armazenadas durante 210 dias a $25^{\circ} \mathrm{C}$ e com $11 \%$ de grau de umidade, resultaram em germinação e vigor finais de 70 e $57 \%$ e 41 e $28 \% 2$, respectivamente. No caso do milho, observa-se que as diferenças nas perdas de germinação e vigor foram causadas pelas diferenças nas frações de lipídios, enquanto que no caso da soja, pelas diferenças nas frações de carboidratos e proteínas. Ellis et al. (1982) e Hong et al. (1996) consideraram que os valores dos coeficientes $K E, C W, C H$ e $C Q$ (Equação 1) são constantes dentro de uma mesma espécie, discordando dos resultados obtidos nestas simulações, embora esses pesquisadores reconheçam que a diferença na composição química de diferentes espécies de sementes seja a principal causa das discrepâncias nos valores desses coeficientes.

As perdas de germinação e vigor para sementes de milho, obtidas experimentalmente e calculadas pelo SEEDSOLVE, por exemplo, para a cultivar SHS4070, podem ser observadas nas Figuras 1 e 2, para as equações do milho e EGL, na temperatura de $25^{\circ} \mathrm{C}$ e graus de umidade de 11 , 13 e 15\%, usando-se ou não fator de correção. Essas perdas para sementes de soja, por exemplo, para a cultivar Garantia, podem ser observadas nas Figuras 3 e 4, para as equações da soja e EGL, na temperatura de $25^{\circ} \mathrm{C}$ e graus de umidade de 9, 11 e 13\%, usando-se ou não fator de correção. Verifica-se nestas figuras (Figuras de 1 a 4) que as equações do aplicativo SEEDSOLVE têm a tendência de superestimar as perdas de germinação e vigor das sementes. Essa tendência, entretanto, transforma-se num fator de segurança na previsão da perda de qualidade das sementes armazenadas. 

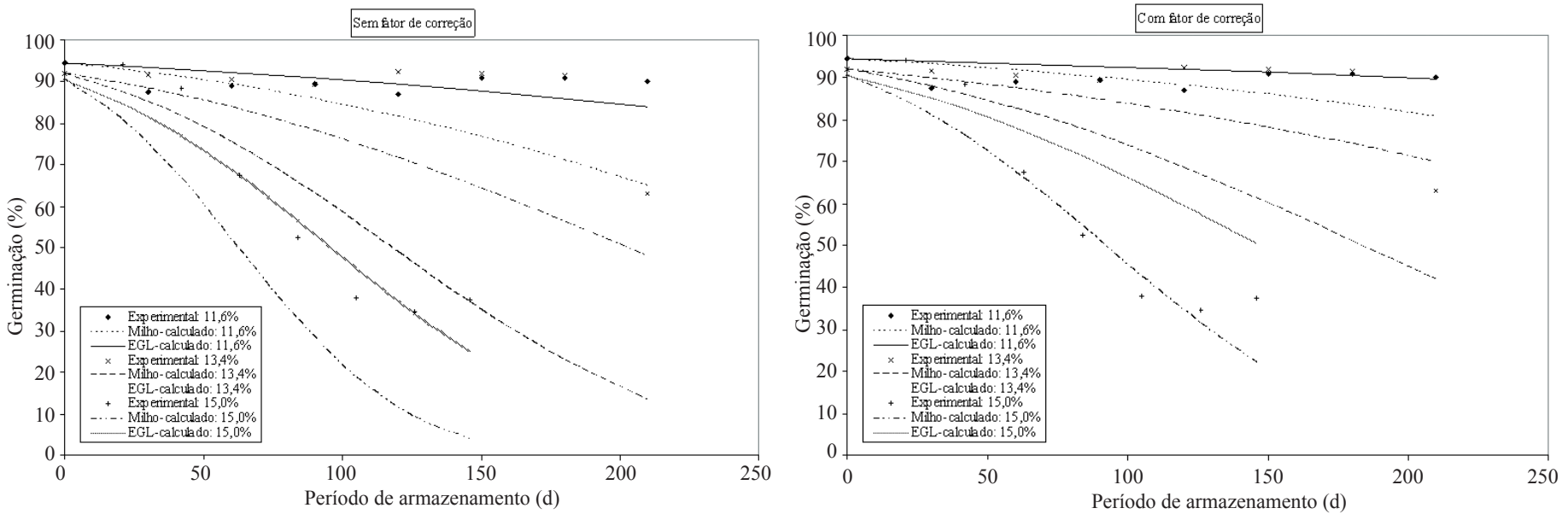

FIGURA 1. Perda da germinação de milho cultivar SHS4070 obtida experimentalmente e calculada pelo SEEDSOLVE para as equações Milho e EGL, temperatura de $25^{\circ} \mathrm{C}$ e graus de umidade de 11,13 e $15 \%$, com e sem fator de correção igual a 1,1 .
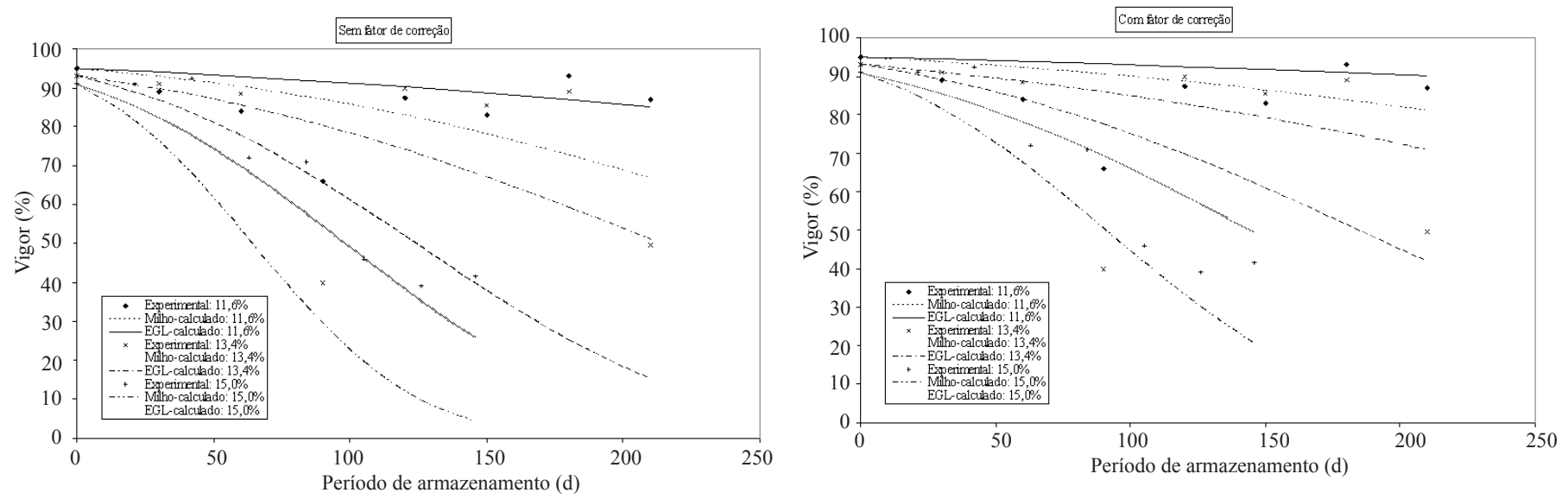

FIGURA 2. Perda do vigor de milho cultivar SHS4070 obtido experimentalmente e calculado pelo SEEDSOLVE para as equações Milho e EGL, temperatura de $25^{\circ} \mathrm{C}$ e graus de umidade de 11,13 e $15 \%$, com e sem fator de correção igual a 1,09 .
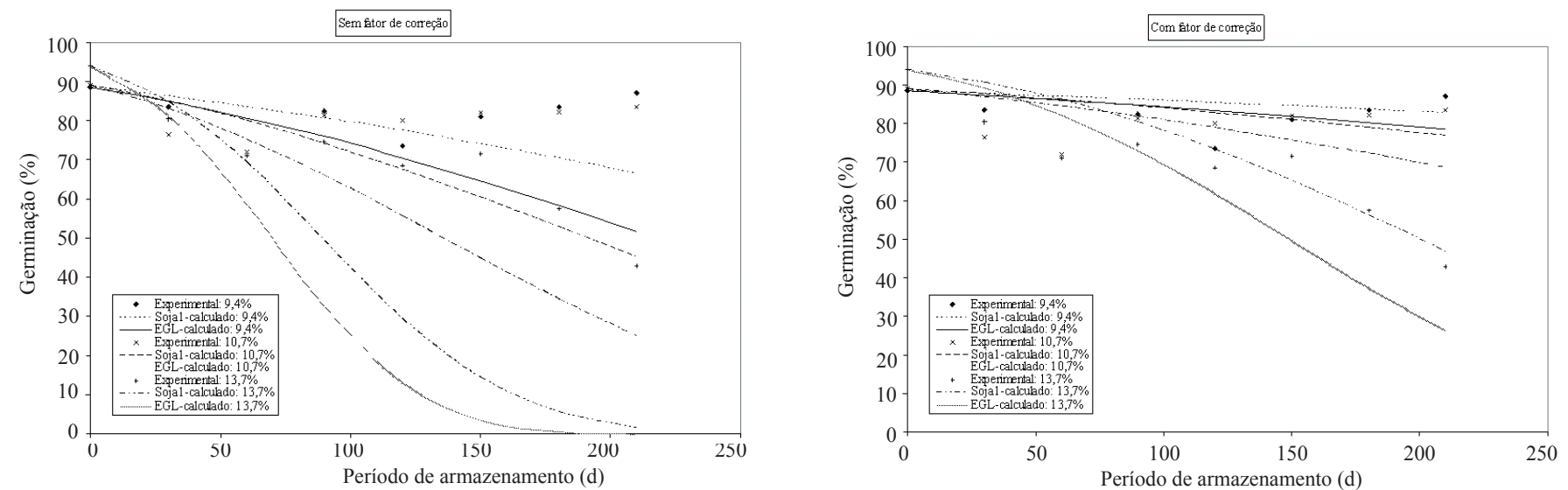

FIGURA 3. Perda da germinação de soja cultivar Garantia obtida experimentalmente e calculada pelo SEEDSOLVE para as equações Soja 1 e EGL, temperatura de $25^{\circ} \mathrm{C}$ e graus de umidade de 9,11 e $13 \%$, com e sem fator de correção igual a 1,2. 

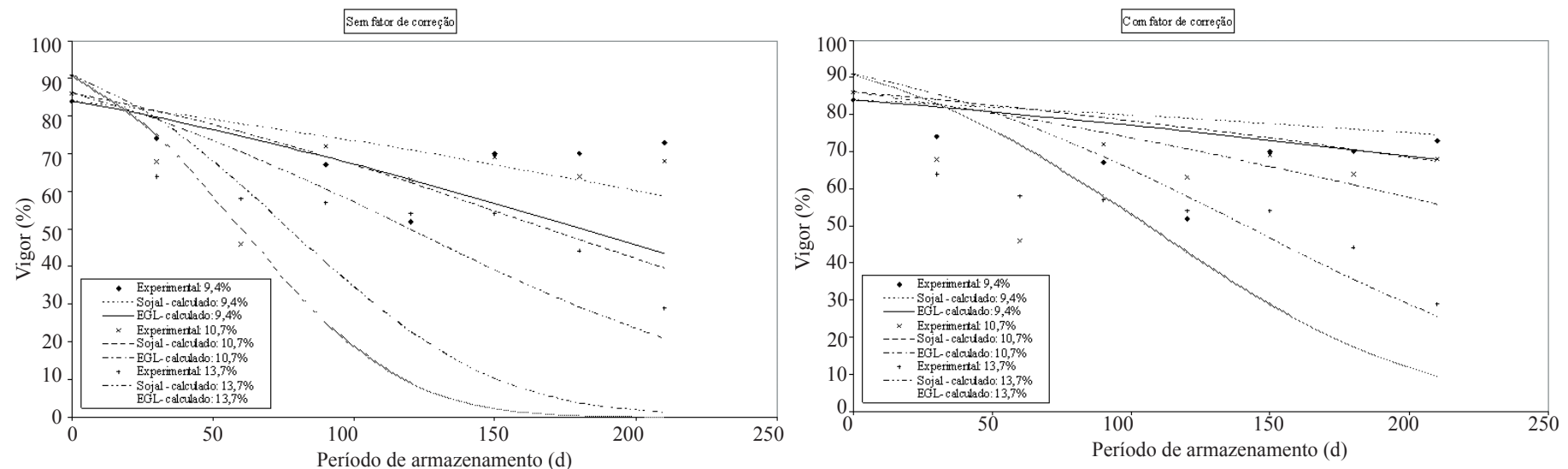

FIGURA 4. Perda do vigor de soja cultivar Garantia obtido experimentalmente e calculado pelo SEEDSOLVE para as equações Soja1 e EGL, temperatura de $25^{\circ} \mathrm{C}$ e graus de umidade de 9,11 e $13 \%$, com e sem fator de correção igual a 1,15 .

Por meio dos resultados obtidos com as simulações utilizando-se o SEEDSOLVE observa-se o potencial do mesmo para a previsão das perdas de germinação e vigor de sementes armazenadas em armazéns comerciais e em bancos de germoplasma. Demonstra-se também a possibilidade de se calibrar as equações escolhidas ao disponibilizar fatores de correção para a germinação e o vigor. A utilização da EGL apresenta grandes vantagens quando a composição química da semente é conhecida, mas a mesma não se encontra dentre as sementes listadas no aplicativo ou não se conhecem os coeficientes da equação de probit da semente (Equação 1).

Nas simulações foram utilizadas condições constantes de temperatura e grau de umidade das sementes, mas o aplicativo permite simular também condições variáveis, situação esta que acontece, por exemplo, quando se usam embalagens de papel multifoliado, as quais permitem troca de vapor entre as sementes e o ambiente.

\section{CONCLUSÃO}

O aplicativo computacional SEEDSOLVE prediz com razoável precisão as perdas de germinação e vigor de sementes de milho e de soja armazenadas.

\section{REFERÊNCIAS}

BEWLEY, J.; BLACK, M. Seeds: physiology of development and germination. 2ed. New York: Plenum Press, 1994. $445 \mathrm{p}$.
BRASIL. Ministério da Agricultura e Reforma Agrária. Secretaria Nacional de Defesa Agropecuária. Departamento Nacional de Defesa Vegetal. Coordenação de Laboratório Vegetal. Regras para análise de sementes. Brasília, DF, 1992. $365 \mathrm{p}$.

CÍCERO, S.M.; VIEIRA, R.D. Teste de frio. In: VIEIRA, R.D. ;CARVALHO, N.M. de. Testes de vigor em sementes. Jaboticabal: UNESP/FCAV, 1994. p.151-164.

ELLIS, R. H.; ROBERTS, E. H. Improved equations for the prediction of seed. longevity. Annals of Botany, v.45, p.1330, 1980.

ELLIS, R.H.; OSEI-BONSU, K.; ROBERTS, H. The influence of genotype, temperature and moisture on seed longevity in chickpea, cowpea and soybean. Annals of Botany, v.50, p.69-82, 1982.

FABRIZIUS, E.; TEKRONY, D.; EGLI, D. B.; RUCKER, M. Evaluation of a viability model for predicting soybean seed germination during warehouse storage. Crop Science. v.39, p.194-201, 1999.

FINNEY, D.J. Probit analysis. 3.ed. Cambridge: University Press, London, 1971. 333 p.

FRANÇA NETO, J.B. FRANÇA NETO, J.B. KRZYZANOWSKI, F.C.; COSTA, N.P. da. O teste de tetrazólio em sementes de soja. Londrina: EMBRAPACNPSo, 1998. 72p. (EMBRAPA-CNPSo, Documentos, 116).

FRANÇA NETO, J. de B. O teste tetrazólio em Sementes de Soja. In: VIEIRA, R.D.; CARVALHO, N.M. (Ed.). Testes 
de vigor em sementes. Jaboticabal, FUNEP/UNESP, 1994. p.87-102.

HONG, T.D., LININGTON, S., ELLIS, R.H. Seed storage behaviour: a compendium. Handbooks for Genebanks: No. 4. International Plant Genetic Resources Institute, Rome, 1996. 120p.

PREGNOLATTO, W.; PREGNOLATTO, N.P. (Coord.). Normas analíticas do Instituto Adolfo Lutz: métodos químicos e físicos para analise de alimentos. 3. ed. São Paulo: Instituto Adolfo Lutz, 1985. v.1

MAURI, A. L.; ARAUJO, E.F.; SINÍCIO, R.; REIS, M.S.; DIAS, D.C.F.S; CAMPOS, J.A. Equacionamento da qualidade inicial de semente de soja no modelo de probit. Revista Brasileira de Armazenamento, v.32, n.1, p.14-22, 2007.

MEAD, A.; GRAY, D. Prediction of seed longevity: a modification of the shape of the Ellis and Roberts seed survival curves. Seed Science Research, v.9, p.63-73, 1999.

MOORE, R. P. Handbook on tetrazolium testing. Zurich: International Seed Testing Association, 1985. 99 p.

PIETA FILHO, C.; ELLIS, R.H. Estimating the value of the seed lot constant (Ki) of the seed viability equation in barley and wheat. Seed Science and Technology, v.20, p.93-99, 1992.

SINÍCIO, R. Equação de longevidade para café (Coffea arabica). Revista Brasileira Engenharia na Agricultura, 2007a. (Submetido para publicação)

SINÍCIO, R. Generalised longevity model for orthodox seeds. Biosystems Engineering, v.89, n.1, p.85-92, 2004.

SINÍCIO, R. Inovação UFV- aplicativo computacional para armazenamento de sementes. Relatório Técnico do Projeto FAPEMIG TEC 742/06. Departamento de Fitotecnia, UFV, Viçosa, 2007b. Não publicado.

SINÍCIO, R.; MAURI, A.L.; ARAUJO, E.F. Equacionamento da longevidade de sementes de tomate (Lycopersicum esculentum Mill). Revista Brasileira de Armazenamento, v.33, n.2, p. 127-133, 2008.

USBERTI, R.; GOMES, R.B.R. Seed viability constants for groundnut. Annals of Botany, Oxford, v.82, p.691-694, 1998.

VERTUCCI, C. W.; ROOS, E. E. Theoretical bases of protocols for seed storage. Plant Physiolology, v.94, p.10191023, 1990. 